\title{
1 On negative induced polarization in frequency domain measurements
}

$3{ }^{1}$ Department of Earth and Environmental Sciences, Rutgers University, Newark, New Jersey,

$4 \quad$ USA

$5 \quad 2$ Lancaster Environment Centre, Lancaster University, Lancaster, UK

6

7 Abbreviated title: Frequency domain negative IP effects

8

9 Corresponding author:

10 Chen Wang

11 Phone: +1 973-353-5100; Fax: +1 973-353-1965;

12 Email: cw701@scarletmail.rutgers.edu 


\section{Summary}

15 Induced polarization (IP) has been widely used to non-invasively characterize electrical 16 conduction and polarization in the subsurface resulting from an applied electric field. Earth

17 materials exhibit a lossy capacitance defined by an intrinsic negative phase in frequency-domain 18 IP (FDIP) or positive intrinsic chargeability in time-domain IP (TDIP). However, error-free 19 positive apparent phase or negative apparent chargeability (i.e., negative IP effects) can occur in

20 IP measurements over heterogeneous media. While negative IP effects in TDIP datasets have been

21 discussed, no studies have addressed this topic in detail for FDIP measurements. We describe 22 theory and numerical modeling to explain the origin of negative IP effects in FDIP measurements.

23 A positive apparent phase may occur when a relatively high polarizability feature falls into 24 negative sensitivity zones of complex resistivity measurements. The polarity of the apparent phase

25 is determined by the distribution of subsurface intrinsic phase and resistivity, with the resistivity 26 impacting the apparent phase polarity via its control on the sensitivity distribution. A physical 27 explanation for the occurrence of positive apparent phase data is provided by an electric circuit 28 model representing a four-electrode measurement. We also show that the apparent phase polarity 29 will be frequency dependent when resistivity changes significantly with frequency (i.e. in the 30 presence of significant IP effects). Consequently, negative IP effects manifest themselves in the 31 shape of apparent phase spectra recorded with multi-frequency (spectral IP) datasets. Our results

32 imply that positive apparent phase measurements should be anticipated and should be retained 33 during inversion and interpretation of single frequency and spectral IP datasets.

35 Key words: Electrical properties; Hydrogeophysics; Electromagnetic theory 


\section{Introduction}

Induced polarization (IP), a non-invasive electrical geophysical technique for subsurface

characterization, has been widely used in various fields including hydrogeology, engineering, mining exploration and environmental problems (e.g., Pelton et al. 1978; Slater \& Lesmes 2002; Flores et al. 2012; Saneiyan et al. 2019). IP measures both electrical conduction (i.e., resistivity) and polarization in a porous medium, therefore providing additional information beyond the direct current resistivity method. The polarization is quantified by either a chargeability in time-domain IP (TDIP) or a phase in frequency-domain IP (FDIP) measurements (Binley \& Kemna 2005). The intrinsic capacitive properties of Earth materials are characterized by a positive intrinsic chargeability (in TDIP) or a negative intrinsic phase when expressed in impedance or complex resistivity space (in FDIP). One would therefore expect a positive apparent (measured) chargeability, or equivalently a negative apparent (measured) phase, which we define here as the normal (or positive) recorded IP response (Ward 1988).

In field data acquisition, a negative IP response, i.e., a negative apparent chargeability or a positive apparent phase, is sometimes observed in the measurements. Such negative IP measurements are often treated as errors and deleted during the data inversion or interpretation (e.g., Mary et al. 2016; Ntarlagiannis et al. 2016; Kelter et al. 2018; Garcia-Artigas et al. 2020). While negative IP responses may indeed reflect measurement artifacts, they can also result from

54 the distortion of the electric field for certain types of heterogeneity close to the electrodes. Negative 55 IP effects in TDIP measurements resulting from such effects have been investigated (Nabighian \& 56 Elliot 1976; Sumner 1976; Komarov 1980; Dahlin \& Loke 2015). Dahlin \& Loke (2015) conclude 57 that negative apparent chargeability results when highly polarizable features fall within zones of 
negative resistivity measurement sensitivity for the utilized electrode configuration. They found that the resistivity distribution influences the occurrence and magnitude of negative apparent

60 chargeability data. Such negative IP measurements provide information about the distribution of

61 features in the subsurface and should not simply be removed during data processing (Binley 2015;

62 Dahlin \& Loke 2015).

63 Negative IP effects in FDIP have seldom been reported and studied. Luo and Zhang (1998)

64 presented analytical solutions that predict a positive apparent phase for a buried polarizable sphere

65 measured by a dipole-dipole array. Some recent complex resistivity imaging studies (Flores

66 Orozco et al. 2018; Liu et al. 2017) reported positive apparent phase measurements and included

67 them in the inversion per recommendations of Dahlin \& Loke (2015) for TDIP datasets. Although

68 frequency and time domain signals are in principle equivalent via the Fourier transform when the

69 frequency/time range is adequately large, the two commonly measured IP parameters, FDIP 70 apparent phase and TDIP apparent chargeability, are not directly equivalent.

71 The apparent chargeability equation developed by Seigel (1959), extended by V. Komarov

72 and colleagues in Russia shortly after Seigel's publication (Komarov 1960), provides a theoretical

73 explanation for negative IP in TDIP measurements. To the knowledge of the authors, no equivalent

74 formulation to explain the existence of negative IP in FD measurements has been presented.

75 Considering the commonly established approximate proportionality between phase and

76 chargeability (e.g., Van Voorhis et al. 1973; Lesmes \& Frye 2001), we might expect similarities

77 in the behavior of negative IP in FDIP measurements to that observed in TDIP reported by Dahlin

78 \& Loke (2015). However, the significance of negative IP effects in FDIP measurements remains

79 poorly understood, especially with respect to spectral IP where the frequency dependence of IP 
80 measurements is recorded. In this study, we integrate theory, numerical modeling, equivalent

81 electric circuits and laboratory measurements to comprehensively investigate negative IP effects

82 in FDIP, including single frequency and spectral IP measurements.

\section{2. Theory of negative IP effects}

$85\left(\rho^{*}\right)$ or its inverse, the complex conductivity $\left(\sigma^{*}\right)$ :

$$
\rho^{*}=\left|\rho^{*}\right| e^{i \varphi}=\frac{1}{\sigma^{*}}
$$

86 where $\left|\rho^{*}\right|$ is the complex resistivity magnitude, $\varphi$ is the complex resistivity phase $(\varphi \leq 0)$ and $i$ is

87 the imaginary unit with $i^{2}=-1$. Both $\rho^{*}$ and $\sigma^{*}$ can also be presented in terms of real and imaginary 88 components that are directly related to the physical (e.g., pore geometry) and chemical properties 89 of the subsurface.

Field scale FDIP data are most commonly acquired using a four-electrode arrangement at

91 the Earth surface. Two electrodes inject a known sinusoidal alternating electrical current $\left(\tilde{I}_{0}\right)$ at

92 various frequencies, while the other two electrodes record the resultant sinusoidal voltage (or

93 potential difference, $\Delta \tilde{U}$ ). According to Ohm's Law, the measured impedance $Z_{\text {app }}^{*}$ (with magnitude

$94\left|Z_{\text {app }}^{*}\right|$ and $\left.\varphi_{\text {app }}\right)$ is determined as,

$$
Z_{\text {app }}^{*}=\left|Z_{\text {app }}^{*}\right| e^{i \varphi_{\text {app }}}=\frac{\Delta \widetilde{U}}{\tilde{I}_{0}}=\frac{|\Delta \widetilde{U}| \sin \left(\omega t+\varphi_{\Delta \mathrm{U}}\right)}{\left|\tilde{I}_{0}\right| \sin (\omega t)}=\frac{|\Delta \widetilde{U}|}{\left|\tilde{I}_{0}\right|} e^{i \varphi_{\Delta \mathrm{U}}}
$$

95 where $\omega$ is the angular frequency, $t$ is time, $\left|\tilde{I}_{0}\right|$ is the current amplitude, $|\Delta \tilde{U}|$ is the voltage

96 amplitude and $\varphi_{\Delta \mathrm{U}}$ is the phase shift of the voltage sinusoid relative to the current sinusoid $\tilde{I}_{0}$ 
97 (defined as the zero phase reference). The apparent complex resistivity $\rho_{\text {app }}^{*}$ (with magnitude $\left|\rho_{\text {app }}^{*}\right|$

98 and the same phase $\varphi_{\text {app }}$ as that of $Z_{\text {app }}^{*}$ ) is determined using the geometric factor of the applied 99 electrode array $K$,

$$
\rho_{\text {app }}^{*}=\left|\rho_{\text {app }}^{*}\right| e^{i \varphi_{\text {app }}}=K Z_{\text {app }}^{*}=K\left|Z_{\text {app }}^{*}\right| e^{i \varphi_{\text {app }}} .
$$

$100 \rho_{\text {app }}^{*}$ is the complex resistivity of a homogeneous space equivalent to the value of $Z_{\text {app }}^{*}$ resulting 101 from application of Eq. (3). Eqs. (2) and (3) show that $\rho_{\text {app }}^{*}, Z_{\text {app, }}^{*}$ and $\Delta \tilde{U}$ are linearly related 102 parameters with differing magnitude but the same phase value.

103 For a heterogeneous subsurface with a two-dimensional distribution of intrinsic complex 104 resistivity $\rho^{*}$ (i.e., $\rho^{*}$ varies in horizontal $x$ and vertical $z$ but constant in $y$ direction), the potential $105 U$ at coordinate $(x, y, z)$ due to a point current source $I$ is described by the Fourier transformed 106 Poisson's equation (e.g., Kemna 2000; Binley 2015),

$$
\begin{gathered}
\frac{\partial}{\partial x}\left(\frac{1}{\rho^{*}} \frac{\partial v^{*}}{\partial x}\right)+\frac{\partial}{\partial z}\left(\frac{1}{\rho^{*}} \frac{\partial v^{*}}{\partial z}\right)-\frac{v^{*} k^{2}}{\rho^{*}}=-I \delta(x) \delta(z), \\
U(x, y, z)=\frac{1}{\pi} \int_{0}^{\infty} v^{*}(x, k, z) \cos (k y) d k,
\end{gathered}
$$

107 where $\delta$ is the Dirac delta function, $v^{*}$ is the Fourier transformed complex voltage and $k$ is the wave 108 number. Eqs. (4) and (5) are solved numerically via discretization, for example using the finite 109 element method. The superposition of calculated potentials at the potential (voltage recording) 110 electrodes and application of Eqs. (2) and (3) yields the $\rho_{\text {app }}^{*}$ of four-electrode measurements 111 acquired over a heterogeneous $\rho^{*}$ subsurface. 
113 subsurface modeled by a number of small cells with each cell $j(j=1,2, \ldots, M)$ characterized by

114 an intrinsic complex resistivity $\rho_{\mathrm{j}}^{*}$ (with magnitude $\left|\rho_{\mathrm{j}}^{*}\right|$ and phase $\varphi_{\mathrm{j}}$ ). If we consider cells

115 parameterized in terms of the logarithms, $\ln \rho_{\mathrm{j}}^{*}$, and measurements equivalently expressed as

$116 \ln \rho_{\text {app }}^{*}$, then for a single four-electrode measurement, the sensitivity to the cell $j\left(S_{\mathrm{j}}^{*}\right)$ quantifies how

117 the change in $\ln \rho_{\mathrm{j}}^{*}$ changes $\ln \rho_{\mathrm{app}}^{*}$,

$$
S_{\mathrm{j}}^{*}=\frac{\partial \ln \rho_{\mathrm{app}}^{*}}{\partial \ln \rho_{\mathrm{j}}^{*}}=\frac{\partial \ln \left(\left|\rho_{\mathrm{app}}^{*}\right| e^{\varphi_{\mathrm{app}} i}\right)}{\partial \ln \left(\left|\rho_{\mathrm{j}}^{*}\right| e^{\varphi_{\mathrm{j}} i}\right)}=\frac{\partial\left(\ln \left|\rho_{\mathrm{app}}^{*}\right|+\varphi_{\mathrm{app}} i\right)}{\partial\left(\ln \left|\rho_{\mathrm{j}}^{*}\right|+\varphi_{\mathrm{j}} i\right)}
$$

118 Different from a conventional direct current (DC) resistivity measurement, $S_{\mathrm{j}}^{*}$ of the FDIP 119 measurement is a complex number. As the derivatives of the complex functions in Eq. (6) satisfy 120 the Cauchy-Riemann conditions (Kemna 2000), the following sensitivity components can be 121 expressed as the real part of $S_{\mathrm{j}}^{*}$ :

$$
S_{\mathrm{j}}=\frac{\partial \ln \left|\rho_{\mathrm{app}}^{*}\right|}{\partial \ln \left|\rho_{\mathrm{j}}^{*}\right|}=\frac{\partial \varphi_{\mathrm{app}}}{\partial \varphi_{\mathrm{j}}}
$$

122 The imaginary part of $S_{\mathrm{j}}^{*}$ is,

$$
S_{\mathrm{j}, \mathrm{im}}=\frac{\partial \ln \left|\rho_{\mathrm{app}}^{*}\right|}{\partial \varphi_{\mathrm{j}}}=-\frac{\partial \varphi_{\mathrm{app}}}{\partial \ln \left|\rho_{\mathrm{j}}^{*}\right|}
$$

123 Although we mainly focus on the discussion of a single four-electrode measurement, it should be 124 noted that a matrix comprising of $S_{\mathrm{j}}$ from a sequence of four-electrode measurements is the 125 Jacobian matrix used, for example, in a gradient-based inverse problem. In Eq. (7), the sensitivity 
126 expressed in terms of complex resistivity magnitude is equivalent to that obtained for DC 127 resistivity measurements, which can take either positive or negative values. An increase of $\mid \rho_{\mathrm{j}}$. 128 a positive $S_{\mathrm{j}}$ zone will increase $\left|\rho_{\mathrm{app}}^{*}\right|$, whereas an increase of $\left|\rho_{\mathrm{j}}^{*}\right|$ in a negative $S_{\mathrm{j}}$ zone will decrease $129\left|\rho_{\text {app }}^{*}\right|$. An equivalent pattern holds for the phase terms as shown in Eq. (7). To illustrate, assume 130 that the subsurface space has zero phase (i.e., is non-polarizable), and thus $\varphi_{\text {app }}=0$. If the phase of 131 an arbitrary cell $\varphi_{\mathrm{j}}$ decreases slightly to a negative value (i.e., becomes polarizable), $\varphi_{\text {app }}$ will 132 decrease to be $<0$ if this polarizable cell is located in a zone of positive $S_{\mathrm{j}}$. However, $\varphi_{\text {app }}$ may 133 increase to be $>0$ (i.e., negative IP signal) if this polarizable cell is in a zone of negative $S_{\mathrm{j}}$. This 134 provides a theoretical basis for the presence of positive $\varphi_{\text {app }}$ (negative IP effects) in FDIP 135 measurements, i.e., $\varphi_{\text {app }}>0$ is possible although all $\varphi_{\mathrm{j}} \leq 0$. The imaginary sensitivity (Eq. 8) plays 136 a negligible role as shown later.

137 While the above arguments are based on the analysis of a single cell $\varphi_{\mathrm{j}}$ and $S_{\mathrm{j}}$, a more 138 generalized way is to consider the collective impacts from all the cells. Kemna (2000) exploited 139 the expression in Eq. (7) by forming a "final phase improvement" in the inversion of complex 140 resistivity data once satisfactory matching of the resistivity magnitudes was achieved. Building on 141 this, consider an expression for the inversion of phase angles using the Gauss-Newton approach 142 (neglecting any damping or regularization for simplicity) (e.g., Kemna 2000; Binley 2015),

$$
\begin{gathered}
{\left[\boldsymbol{S}^{T} \boldsymbol{S}\right] \Delta \boldsymbol{m}=\boldsymbol{S}^{T}\left[\boldsymbol{d}-F\left(\boldsymbol{m}_{k}\right)\right]} \\
\boldsymbol{m}_{k+1}=\boldsymbol{m}_{k}+\Delta \boldsymbol{m}
\end{gathered}
$$

143 where $\boldsymbol{S}$ is the sensitivity matrix for a sequence of four-electrode measurements, $\boldsymbol{d}$ is a vector of 144 measured data ( $\varphi_{\text {app }}$ in this case), $F$ is the forward modeling operator, $\boldsymbol{m}$ is a vector of the model 
145 parameters ( $\varphi_{\mathrm{j}}$ in this case), $\boldsymbol{m}_{k}$ and $\boldsymbol{m}_{k+1}$ are the model parameter set at iteration $k$ and $k+1$, 146 respectively, $\Delta \boldsymbol{m}$ is the model parameter update at iteration $k$. Assuming that the inversion is 147 achieved with only one step from a starting model with all $\varphi_{\mathrm{j}}=0$, we have $\boldsymbol{m}_{k}=\mathbf{0}, F\left(\boldsymbol{m}_{k}\right)=\mathbf{0}, \boldsymbol{m}_{k+1}$ $148=\Delta \boldsymbol{m}$. We can then write Eq. (9) as,

$$
S \Delta \boldsymbol{m}=\boldsymbol{d} .
$$

149 In this simplified one-step inversion, $\Delta \boldsymbol{m}$ is essentially the final model that matches $\boldsymbol{d}$. Again, if 150 we only consider a single four-electrode measurement, Eq. (11) gives,

$$
\sum_{\mathrm{j}=1}^{M} S_{\mathrm{j}} \varphi_{\mathrm{j}}=\varphi_{\mathrm{app}} .
$$

151 This approximation describes the collective impacts of $\varphi_{\mathrm{j}}$ and $S_{\mathrm{j}}$ from all the cells. Eq. (12) 152 explicitly shows that even when all $\varphi_{\mathrm{j}} \leq 0(j=1,2, \ldots, M), \varphi_{\text {app }}$ can be positive when relatively 153 more negative $\varphi_{\mathrm{j}}$ cells concurrently have $S_{\mathrm{j}}<0$. The polarity of $\varphi_{\text {app }}$ will therefore depend on the 154 relative values of intrinsic phase and the sensitivity, where the latter is affected by the quadrupole 155 geometry and distribution of the intrinsic resistivity.

156 A similar association between negative IP signals and the sensitivity distribution is 157 recognized in TDIP data (Dahlin \& Loke 2015). In TDIP, a unidirectional current is driven 158 between the current electrodes for a period of time and then abruptly switched off. The voltage $V_{\mathrm{p}}$ 159 recorded right before switching off is used to obtain the apparent DC resistivity $\rho_{\text {app }}^{(\mathrm{DC})}$ (assuming 160 the current injection is long enough to approximate a DC condition). After switching off the current, $161 V_{\mathrm{p}}$ drops suddenly to a secondary voltage $V_{\mathrm{s}}$, which then decays with time. Seigel (1959) defined 162 the apparent chargeability ( $\left.m_{\text {app }}\right)$ as the ratio of $V_{\mathrm{s}}$ to $V_{\mathrm{p}}$ to quantify the TDIP polarization strength. 
163 Considering the same scenario where the subsurface is modeled by $M$ small cells with index $j$, the

164 theoretical relationship between a single measure of $\rho_{\mathrm{app}}^{(\mathrm{DC})}$ and $m_{\mathrm{app}}$, and the intrinsic parameters

$165 \rho_{\mathrm{j}}^{(\mathrm{DC})}$ and $m_{\mathrm{j}}$ making up the subsurface is (Seigel, 1959),

$$
m_{\mathrm{app}}=\sum_{\mathrm{j}=1}^{M} \frac{\partial \ln \rho_{\mathrm{app}}^{(\mathrm{DC})}}{\partial \ln \rho_{\mathrm{j}}^{(\mathrm{DC})}} m_{\mathrm{j}}=\sum_{\mathrm{j}=1}^{M} S_{\mathrm{j}}^{(\mathrm{DC})} m_{\mathrm{j}} .
$$

166 where $S_{\mathrm{j}}^{(\mathrm{DC})}$ is the sensitivity to a cell $j$ in terms of DC resistivity, being analogous to the sensitivity

167 in terms of complex resistivity magnitude (Eq. (7)). Eq. (13) has essentially the same structure as

168 Eq. (12). With all $m_{\mathrm{j}} \geq 0(j=1,2, \ldots, M)$ for Earth materials, the polarity of $m_{\text {app }}$ is decided by the

169 polarity of $S_{\mathrm{j}}^{(\mathrm{DC})}$ and the relative values of $m_{\mathrm{j}}$. Eq. (13) predicts that negative $m_{\text {app }}$ is possible when

170 features with relatively high $m_{\mathrm{j}}$ fall into negative sensitivity zones, providing theoretical support

171 for the negative IP effects in TDIP. In practice, $m_{\text {app }}$ defined by Seigel (1959) is difficult to measure

172 and an integral chargeability is instead commonly measured (Binley 2015), which can exhibit

173 equivalent negative IP effects (Dahlin \& Loke 2015).

174 We stress that laboratory measurements of intrinsic complex resistivity or chargeability on

175 a core or soil sample (considered homogeneous at the measurement scale but in fact likely to

176 contain small scale heterogeneity) can never exhibit negative IP effects when 1D current flow is

177 maintained. Such negative IP effects sometimes reported in the literature (e.g., Abdulsamad et al.

178 2016; Saneiyan et al. 2018; Bate et al. 2020) can only arise from measurement errors. 


\section{Numerical modeling}

To investigate the behavior of the $\varphi_{\text {app }}$ polarity, 2D forward modeling of synthetic intrinsic

complex

resistivity

distributions

was

performed

using

cR2

184 (http://www.es.lancs.ac.uk/people/amb/Freeware/cR2/cR2.htm) in its python wrapper ResIPy

185 (Blanchy et al. 2020). The region of interest of the synthetic model contains 25 electrodes spaced

$1862 \mathrm{~m}$ apart for a total length of $48 \mathrm{~m}$ and extends to $8 \mathrm{~m}$ depth (Figure 1). A quadrilateral mesh with 187 each mesh cell of size $0.25 \times 0.25 \mathrm{~m}$ (i.e., 8 nodes per electrode) was used for the computations.

188 In this case, each mesh cell corresponds to a small cell $j$ described in Section 2. This mesh extends

189 a large distance beyond the region of interest and incorporates boundary conditions that 190 approximate an infinitely large model space. Different intrinsic resistivity and phase values were 191 assigned to different regions to illustrate specific aspects of negative IP effects predicted by theory.

192 Forward models were run to determine $\varphi_{\text {app }}$ of either a single four-electrode measurement or to 193 construct a pseudosection from a sequence of measurements. The four electrodes include a pair of 194 electrodes (positive $\mathrm{C}+$ and negative $\mathrm{C}$-) for current injection and a pair of electrodes (positive $\mathrm{P}+$ 195 and negative P-) for voltage (potential) measurements.

196 The sensitivity distribution for a single four-electrode measurement on a selected synthetic 197 model was computed using cR2, with a vector of $S_{\mathrm{j}}^{*}$ corresponding to each mesh cell in the 198 modeling space as the output (Eq. 6). No noise was added to the forward modeling and sensitivity 199 distribution calculation so as to avoid the complicating effects of random errors on the modeling 200 results. 
The sensitivity distribution for a dipole-dipole array $(\mathrm{E} 10=\mathrm{C}+, \mathrm{E} 12=\mathrm{C}-, \mathrm{E} 14=\mathrm{P}-, \mathrm{E} 16=\mathrm{P}+)$ and also for a Wenner array $(\mathrm{E} 10=\mathrm{C}+, \mathrm{E} 12=\mathrm{P}+, \mathrm{E} 14=\mathrm{P}-, \mathrm{E} 16=\mathrm{C}-)$ was first computed for a

204 homogeneous, low polarizability half-space $\left(\left|\rho^{*}\right|=100 \Omega \mathrm{m}, \varphi=-1 \mathrm{mrad}\right)$ (Figure 2). The 205 imaginary sensitivity (Eq. (8), Figure 2c and 2d) exerts a negligible control on the measurements 206 as its values are many orders of magnitude less than the real sensitivity (Eq. (7), Figure 2a and 2b).

207 A simulation on a homogenous, high polarizability half-space $\left(\left|\rho^{*}\right|=100 \Omega \mathrm{m}, \varphi=-100 \mathrm{mrad}\right)$ 208 results in similar negligible response in the imaginary sensitivity distribution, again being many 209 orders of magnitude less than the real sensitivity. We therefore refer to the real sensitivity in all 210 future discussion of sensitivity patterns. Different patterns of positive and negative sensitivity are 211 observed for the dipole-dipole (Figure 2a) and Wenner arrays (Figure 2b). The sensitivity of zones 212 away from the electrode array is close to zero, therefore having a negligible effect on the $\rho_{\text {app }}^{*}$ 213 measurement.

214 To illustrate the influence of the sensitivity distribution on the polarity of the measured 215 phase, new forward models were run where $\varphi_{\text {app }}$ of a single measurement using E10, E12, E14 and 216 E16 was computed with a small polarizable cell $\left(\left|\rho^{*}\right|=100 \Omega \mathrm{m}\right.$ and $\left.\varphi=-100 \mathrm{mrad}\right)$ of the same 217 size as a mesh cell $(0.25 \times 0.25 \mathrm{~m})$ placed at various locations in a background non-polarizing half 218 space $\left(\left|\rho^{*}\right|=100 \Omega \mathrm{m}, \varphi=0 \mathrm{mrad}\right)$ (Figure 3a). Starting from the first mesh cell, the polarizable 219 cell was moved to the right and down one cell by one cell to cover the horizontal distance from 15 220 to $24 \mathrm{~m}$ and the depth range from 0 to $6 \mathrm{~m}$ (containing the zone of enhanced sensitivity). With the 221 polarizable cell at each mesh cell location, the apparent phase $\varphi_{\text {app }}$ of a dipole-dipole array $222(\mathrm{E} 10=\mathrm{C}+, \mathrm{E} 12=\mathrm{C}-, \mathrm{E} 14=\mathrm{P}-, \mathrm{E} 16=\mathrm{P}+)$ and a Wenner array $(\mathrm{E} 10=\mathrm{C}+, \mathrm{E} 12=\mathrm{P}+, \mathrm{E} 14=\mathrm{P}-, \mathrm{E} 16=\mathrm{C}-)$ 
223 was computed. Figure 3 shows $\varphi_{\text {app }}$ plotted against the sensitivity of the location with the

224 polarizable cell for the corresponding measurement array. The polarity of $\varphi_{\text {app }}$ is the inverse of the

225 polarity of the sensitivity, i.e., the polarizable cell placed in positive sensitivity zones results in

226 negative $\varphi_{\text {app }}$ and the polarizable cell placed in negative sensitivity zones results in positive $\varphi_{\text {app. }}$

227 The magnitude of the negative IP signal increases linearly with the magnitude of the negative

228 sensitivity.

\subsection{Influence of heterogeneity}

We next investigate the effect of heterogeneity on the sensitivity and hence the $\varphi_{\text {app }}$

232 polarity pattern. A $3 \times 3 \mathrm{~m}$ polarizable block was located between $22.5 \mathrm{~m}$ and $25.5 \mathrm{~m}$ along the 233 line and placed at a depth of $0 \mathrm{~m}$ to $3 \mathrm{~m}$ (Figure $4 \mathrm{a}$ ). The background was set with $\varphi_{\text {bgk }}=-1 \mathrm{mrad}$

234 (low polarization) and $\left|\rho_{\text {bgk }}^{*}\right|=100 \Omega \mathrm{m}$, while the polarizable block was assigned $\varphi_{\text {block }}=-100$

$235 \operatorname{mrad}$ and $\left|\rho_{\text {block }}^{*}\right|$ equal to either 50,100 or $200 \Omega \mathrm{m}$. For each $\left|\rho_{\text {block }}^{*}\right|$ scenario, a $\varphi_{\text {app }}$ pseudosection

236 was computed for a dipole-dipole array sequence with $a=4 \mathrm{~m}$ and $n=1,2,3$ and 4 (i.e., electrodes

237 placed in the order $\mathrm{C}+, \mathrm{C}-, \mathrm{P}-, \mathrm{P}+$ with spacing $a, a \times n$ and $a$ between $\mathrm{C}+$ and $\mathrm{C}-, \mathrm{C}-$ and $\mathrm{P}-$, and

$238 \mathrm{P}$ - and $\mathrm{P}+$, respectively) (Figure 4b). The results show that the resistivity of the polarizable block

239 has a significant influence on the polarity and magnitude of $\varphi_{\text {app }}$ within the zones indicated by the 240 dashed triangles. These $\varphi_{\text {app }}$ values increase from negative to positive (i.e. negative IP effect) as $241\left|\rho_{\text {block }}^{*}\right|$ increases from 50 to $100 \Omega \mathrm{m}$. Higher positive values of $\varphi_{\text {app }}$ (i.e., enhanced negative IP 242 effects) are observed for $\mid \rho_{\text {block }}^{*}$ equal to $200 \Omega \mathrm{m}$. 
244 the presence of the heterogeneity modifies the sensitivity distribution relative to a homogeneous 245 resistivity medium. To illustrate this, a single $\varphi_{\text {app }}$ measurement using E10=C+, E12=C-, E14=P-, $246 \mathrm{E} 16=\mathrm{P}+($ pointed out by arrows in Figure $4 \mathrm{~b})$ is used as an example. The corresponding sensitivity 247 distribution for the three synthetic models with different $\left|\rho_{\text {block }}^{*}\right|$ values is shown in Figure 4c. As $248\left|\rho_{\text {block }}^{*}\right|$ increases from 50 to 100 , and then to $200 \Omega \mathrm{m}, \varphi_{\text {app }}$ increases from $-14 \operatorname{mrad}$ to $9 \mathrm{mrad}$ for 249 the $100 \Omega \mathrm{m}$ block and to $33 \mathrm{mrad}$ for the $200 \Omega \mathrm{m}$ block. This increase of $\varphi_{\text {app }}$ toward more 250 positive values with increasing $\left|\rho_{\text {block }}^{*}\right|$ can be explained by the expansion of the negative sensitivity 251 zones within the polarizable block boundary as $\left|\rho_{\text {block }}^{*}\right|$ increases (Figure 4c). This change in the 252 sensitivity pattern is highlighted by the difference in sensitivity referenced to the sensitivity for the $253\left|\rho_{\text {block }}^{*}\right|=100 \Omega \mathrm{m}$ scenario, where $\left|\rho_{\text {block }}^{*}\right|=50 \Omega \mathrm{m}$ and $\left|\rho_{\text {block }}^{*}\right|=200 \Omega \mathrm{m}$ highlights increased 254 and decrease sensitivity respectively within the block boundary (Figure 4d). This confirms that the 255 resistivity heterogeneity has a significant influence on the polarity of $\varphi_{\text {app }}$ by changing the 256 sensitivity distribution.

257 So far, we have shown that the polarity of $\varphi_{\text {app }}$ is determined by three major factors: (1) the 258 location of polarizable objects relative to positive/negative sensitivity zones; (2) the intrinsic phase 259 of the polarizable objects relative to the surrounding subsurface; (3) the subsurface resistivity 260 heterogeneity that changes the sensitivity patterns. To illustrate the collective impacts of the 261 intrinsic resistivity and intrinsic phase, we computed $\varphi_{\text {app }}$ for a dipole-dipole array $(\mathrm{E} 10=\mathrm{C}+$, 262 E12=C-, E14=P-, E16=P+) using the same model structure and background settings as shown in 263 Figure 4a, but with $\left|\rho_{\text {block }}^{*}\right|$ varying from 20 to $200 \Omega \mathrm{m}$ and $\varphi_{\text {block }}$ varying from -5 to $-120 \mathrm{mrad}$ 
264 (Figure 5a). When $\mid \rho_{\text {block }}^{*}=20,40$ or $60 \Omega \mathrm{m}$, all $\varphi_{\text {app }}$ are negative and become more negative with $265 \varphi$ block changing from -5 to $-120 \mathrm{mrad}$. When $\left|\rho_{\text {block }}^{*}\right|=80,100,120$ or $140 \Omega \mathrm{m}, \varphi_{\text {app }}$ is negative 266 when $\varphi_{\text {block }}$ is small $(-5 \mathrm{mrad})$, but becomes positive when $\varphi_{\text {block }}$ is more negative. At $\left|\rho_{\text {block }}^{*}\right|$ above $267140 \Omega \mathrm{m}$, all $\varphi_{\text {app }}$ are positive even when $\varphi_{\text {block }}$ is only $-5 \mathrm{mrad}$; again, $\varphi_{\text {app }}$ becomes more positive 268 as $\varphi_{\text {block }}$ becomes more negative. A clear transition from negative $\varphi_{\text {app }}$ to positive $\varphi_{\text {app }}$ can be 269 observed in Figure 5a, which shows that a higher $\left|\rho_{\text {block }}^{*}\right|$ relative to $\left|\rho_{\text {bgk }}^{*}\right|$ tends to result in positive $270 \varphi_{\text {app. }}$. The $\varphi_{\text {app }}$ pattern will also be affected by other factors, for example the background phase $\varphi_{\text {bgk }}$. 271 Figure $5 \mathrm{~b}$ presents the $\varphi_{\text {app }}$ change when $\varphi_{\text {bgk }}$ is set to be $-10 \mathrm{mrad}$. In this situation, more points 272 show negative $\varphi_{\text {app }}$ with positive $\varphi_{\text {app }}$ only occurring when $\left|\rho_{\text {block }}^{*}\right|$ is sufficiently large and $\varphi_{\text {block }}$ is 273 sufficiently negative.

274 The shape of the polarizable block also determines the $\varphi_{\text {app }}$ change under various $\left|\rho_{\text {block }}^{*}\right|$ 275 and $\varphi_{\text {block }}$ conditions. Figure $5 \mathrm{c}$ shows the simulation with the same model settings as that in Figure $2765 \mathrm{a}$ except that the vertical extent of the polarizable block is reduced to be between 0 to $1 \mathrm{~m}$. In this 277 case, most of the points show positive $\varphi_{\text {app }}$ due to the increased portions of negative sensitivity 278 zone in the polarizable block. For example, in the case of $\left|\rho_{\text {block }}^{*}\right|=100 \Omega \mathrm{m}$ in Figure $4 \mathrm{c}$, when 279 the vertical extent of the polarizable block is reduced to be between 0 to $1 \mathrm{~m}$, most of the regions 280 within the block would have negative sensitivity. In this situation, positive $\varphi_{\text {app }}$ is more likely as 281 per Eq. (12).

282 The above results were obtained from simple, heterogenous synthetic models. For a real 283 subsurface, the interactions between complicated structures and zones may result in various $\varphi_{\text {app }}$ 284 patterns, making it difficult to generalize about what situations will result in negative IP effects. 
285 One important observation from Figure 5 is that even weakly polarizable objects (e.g., $\varphi_{\text {block }}=-5$

286 and $-10 \mathrm{mrad}$ ) may produce negative IP signals, especially when the objects have high resistivity 287 relative to the background (e.g., polarizable objects characterized by low water content, low 288 porosity or high electrical resistivity pore fluids).

\section{A physical explanation of negative IP effects using an electrical circuit}

We have so far explained the occurrence of negative IP signals using theory and numerical

291 modeling. Next, we seek a more physical explanation as a positive phase implies that the electrical

292 current lags the voltage, which is considered to be non-physical in the presence of IP effect. We

293 use a simplified electrical circuit model to provide a physical explanation for negative IP effects.

294 We consider a subsurface represented by a resistor/impedance network circuit (Figure 6a). A

295 sinusoidal current $\tilde{I}_{0}$ with fixed amplitude $\left|\tilde{I}_{0}\right|$ and zero reference phase is injected between $\mathrm{C}+$ and

296 C-, while the resultant sinusoidal voltage $\Delta \tilde{U}$ (with amplitude $|\Delta \tilde{U}|$ and phase $\varphi_{\Delta \mathrm{U}}$ ) is measured

297 between $\mathrm{P}+$ and $\mathrm{P}$ - in the same manner as a dipole-dipole array. Comparing the relative locations

298 of the circuit components in Figure 6a with Figure 2a, $Z_{1}^{*}$ (with magnitude $\left|Z_{1}^{*}\right|$ and phase $\varphi_{1}$ ) and

$299 Z_{2}^{*}$ (with magnitude $\left|Z_{2}^{*}\right|$ and phase $\varphi_{2}$ ) represent impedance components located in the positive and

300 negative sensitivity zones, respectively. We next evaluate how changes of $Z_{1}^{*}$ or $Z_{2}^{*}$ alter the

301 apparent measured impedance $Z_{\text {app }}^{*}$ (i.e., $\left.\Delta \tilde{U} / \tilde{I}_{0}\right)$.

302 To make the analysis simple, we set all other circuit components to be pure resistors 303 (represented by symbol ' $R$ '). According to Figure $6 \mathrm{a}, \tilde{I}_{0}$ exits the network via 'C-' by passing $Z_{1}^{*}$,

$304 Z_{2}^{*}, R_{3}, R_{4}$ and $R_{5}$, which gives $\tilde{I}_{0}=\tilde{I}_{1}+\tilde{I}_{4}+\tilde{I}_{2}$ with $\tilde{I}_{2}=\tilde{I}_{3}+\tilde{I}_{5}$, where $\tilde{I}_{1}$ to $\tilde{I}_{5}$ are the currents flowing 305 through the corresponding impedance/resistors. We simplify this network circuit to an equivalent 
306 linear circuit that is easier to analyze (Figure 6b). In Figure 6b, $R_{3 \mathrm{~s}}, R_{4 \mathrm{~s}}$ and $R_{5 \mathrm{~s}}$ represent the 307 equivalent total resistances of the current path prior to $R_{3}, R_{4}$, and $R_{5}$ respectively, while other 308 components are identical to those shown in Figure 6a. The total impedance of this circuit is,

$$
Z_{\mathrm{tot}}^{*}=\frac{\widetilde{U}_{0}}{\tilde{I}_{0}}=\frac{1}{\frac{1}{Z_{1}^{*}}+\frac{1}{R_{4 \mathrm{~s}}+R_{4}}+\frac{1}{\frac{\left(R_{5 \mathrm{~s}}+R_{5}\right)\left(R_{3 \mathrm{~s}}+R_{3}\right)}{\left(R_{5 \mathrm{~s}}+R_{5}\right)+\left(R_{3 \mathrm{~s}}+R_{3}\right)}+Z_{2}^{*}}}=\frac{1}{\frac{1}{Z_{1}^{*}}+a+\frac{1}{b+Z_{2}^{*}}}
$$

309 where $\tilde{U}_{0}$ is the total voltage between $\mathrm{C}+$ and $\mathrm{C}-$ and $a$ and $b$ are real number constants as 310 resistances $R_{3 \mathrm{~s}}, R_{3 \mathrm{~s}}, R_{4 \mathrm{~s}}, R_{4}, R_{5 \mathrm{~s}}$ and $R_{5}$ do not change. According to the voltage divider rule,

$$
\frac{\Delta \widetilde{U}}{\widetilde{U}_{0}}=\frac{R_{3}}{\left(R_{3 \mathrm{~s}}+R_{3}\right)} \frac{b}{b+Z_{2}^{*}}=c \frac{b}{b+Z_{2}^{*}},
$$

311 where $c$ is again a real number constant representing a constant resistance term. Combining Eq. 312 (2), Eq. (14) and (15) gives,

$$
\left|Z_{\text {app }}^{*}\right| e^{\varphi_{\mathrm{app}} i}=\frac{\Delta \widetilde{U}}{\tilde{I}_{0}}=\frac{b c}{\frac{b+Z_{2}^{*}}{Z_{1}^{*}}+a Z_{2}^{*}+a b+1} .
$$

313 Considering that the intrinsic phase shifts of the earth materials are small negative values $(-0.2<$

$314 \varphi<0), \cos \varphi \approx 1$ and $\varphi \approx \sin (\varphi) \approx \tan (\varphi) \approx \tan ^{-1}(\varphi)$. Any impedance term $Z^{*}$ can then be written in 315 rectangular form as $Z^{*}=\left|Z^{*}\right| \cos (\varphi)+i\left|Z^{*}\right| \sin (\varphi) \approx\left|Z^{*}\right|+i\left|Z^{*}\right| \varphi$. When $Z_{1}^{*}$ (located in the positive 316 sensitivity zone of the array) is polarizable (i.e., $\varphi_{1}<0$ ) and $Z_{2}^{*}$ (located in the negative sensitivity 317 zone) is non-polarizable (i.e., $\varphi_{2}=0$ ), Eq. (16) gives, 


$$
\varphi_{\mathrm{app}} \approx \varphi_{1} \frac{b+\left|Z_{2}^{*}\right|}{b+\left|Z_{2}^{*}\right|+a\left|Z_{1}^{*}\right|\left|Z_{2}^{*}\right|+a b\left|Z_{1}^{*}\right|+\left|Z_{1}^{*}\right|},
$$

318 which explicitly shows that $\varphi_{\text {app }}<0$, being a measurement signal with normal polarity. On the 319 contrary, if $Z_{2}^{*}$ is polarizable (i.e., $\left.\varphi_{2}<0\right)$ and $Z_{1}^{*}$ is non-polarizable (i.e., $\varphi_{1}=0$ ), Eq. (16) results 320 in,

$$
\varphi_{\text {app }} \approx-\varphi_{2} \frac{\left|Z_{2}^{*}\right|+a\left|Z_{1}^{*}\right|\left|Z_{2}^{*}\right|}{b+\left|Z_{2}^{*}\right|+a\left|Z_{1}^{*}\right|\left|Z_{2}^{*}\right|+a b\left|Z_{1}^{*}\right|+\left|Z_{1}^{*}\right|},
$$

321 which gives $\varphi_{\text {app }}>0$, being a measurement signal with negative IP polarity. It can be concluded

322 that the negative IP signals originate from the fact that the impedance is determined from dividing

323 the recorded voltage $\Delta \tilde{U}$ by the input current $\tilde{I}_{0}$ instead of by the current flowing through the

324 impedance across which $\Delta \tilde{U}$ is recorded, i.e., $\tilde{I}_{3}$ in our case. It is the phase difference between $\tilde{I}_{3}$

325 and measured $\tilde{I}_{0}$ that gives the non-physical impression of the current lagging the voltage as

326 implied by a positive phase. The circuit model analogy also explains the impact of sensitivity on

327 the resistivity measurements (i.e., resistance measurement in the circuit model). Considering $Z_{1}^{*}$ 328 and $Z_{2}^{*}$ as pure resistors (i.e., zero phase), Eq. (16) shows that $\left|Z_{\text {app }}^{*}\right|$ increases with the increase of $329\left|Z_{1}^{*}\right|$, whereas it decreases with the increase of $\left|Z_{2}^{*}\right|$.

\section{5. Frequency dependence}

The influence of resistivity and phase variability on the polarity of $\varphi_{\text {app }}$ also has important,

332 hitherto unrecognized, implications for the interpretation of spectral IP datasets. The $\varphi_{\text {app }}$ polarity

333 can vary with frequency if the resistivity of polarizable features changes significantly with

334 frequency, e.g., as observed for electronically conducting materials (e.g., Pelton et al. 1978; Wong 
335 1979). We examine this effect using the same synthetic model structure shown in Figure 4a but 336 assigning various values of frequency independent $\left|\rho_{\mathrm{bgk}}^{*}\right|, \varphi_{\mathrm{bgk}}$ and frequency-dependent $\left|\rho_{\mathrm{block}}^{*}\right|$ 337 and $\varphi_{\text {block}}$. We define the frequency dependence of the polarizability of the block using a Cole338 Cole type model (Cole \& Cole 1941; Pelton et al. 1978) with parameters previously found to fit 339 laboratory experimental data obtained on a zero valent iron-sand mixture (50\% iron by volume) 340 (Slater et al. 2005) (Figure 7a). The spectra cover frequencies from $10^{-3}$ to $10^{4} \mathrm{~Hz}$, with $\mid \rho_{\text {block }}^{*}$ 341 decreasing from 41 to $14 \Omega \mathrm{m}$ (from low to high frequency). The $\varphi_{\text {block }}$ ranges from $-21 \mathrm{mrad}$ to $342174 \mathrm{mrad}$, with the peak occurring at $\sim 1 \mathrm{~Hz}$. The frequency independent background half-space 343 was assigned $\varphi_{\mathrm{bgk}}=-1 \mathrm{mrad}$, with the $\left|\rho_{\mathrm{bgk}}^{*}\right|$ set to either 10,30 or $55 \Omega \mathrm{m}$ in order to simulate 344 scenarios with $\left|\rho_{\text {bgk }}^{*}\right|$ lower, close to or higher than $\left|\rho_{\text {block }}^{*}\right|$ (Figure 7a).

$345 \quad$ Figure $7 \mathrm{~b}$ shows the apparent parameters $\left|\rho_{\text {app }}^{*}\right|$ and $\varphi_{\text {app }}$ from the single measurement for a 346 dipole-dipole array $(\mathrm{E} 10=\mathrm{C}+, \mathrm{E} 12=\mathrm{C}-, \mathrm{E} 14=\mathrm{P}-, \mathrm{E} 16=\mathrm{P}+)$ at various frequencies. Three 347 simulations result in completely different shapes of $\varphi_{\text {app }}$ curves when only the resistivity contrast 348 between the target and the background changes between the simulations. For the highest 349 background resistivity, $\left|\rho_{\text {bgk }}^{*}\right|=55 \Omega \mathrm{m}$, the $\varphi_{\text {app }}$ spectra are negative and display a negative peak 350 similar to the $\varphi_{\text {block }}$ spectrum. When $\left|\rho_{\text {bgk }}^{*}\right|$ is reduced to $30 \Omega \mathrm{m}, \varphi_{\text {app }}$ is negative at high frequencies 351 but increases to be positive below around $20 \mathrm{~Hz}$. Peaks are observed in both positive and negative 352 apparent phase domains. For the lowest background resistivity $\left|\rho_{\text {bgk }}^{*}\right|=10 \Omega \mathrm{m}$, all $\varphi_{\text {app }}$ values 353 become positive and a peak of $\varphi_{\text {app }}$ toward more positive values is observed.

354 The differences among the three $\varphi_{\text {app }}$ curves can be explained by the difference in 355 resistivity of $\left|\rho_{\text {block }}^{*}\right|$ relative to $\left|\rho_{\text {bgk }}^{*}\right|$ and how this difference affects the sensitivity distribution, as 
356 demonstrated in Section 3.2. Positive $\varphi_{\text {app }}$ values are found when $\left|\rho_{\text {block }}^{*}\right| / \rho_{\text {bgk }}^{*} \mid$ is relatively high,

357 being the case when $\left|\rho_{\mathrm{bgk}}^{*}\right|=10 \Omega \mathrm{m}$ for all frequencies and when $\left|\rho_{\mathrm{bgk}}^{*}\right|=30 \Omega \mathrm{m}$ at low frequencies.

358 The $\left|\rho_{\text {app }}^{*}\right|$ spectra also differ between the three simulations, exhibiting a frequency dependence

359 consistent with the polarity of $\varphi_{\text {app }}$. The percentage frequency effect $\left(\operatorname{PFE}=\left(\left|\rho_{\text {app }}^{*}\right| \mathrm{L}-\left|\rho_{\text {app }}^{*}\right| \mathrm{H}\right) /\right.$

$360\left|\rho_{\text {app }}^{*}\right|_{\mathrm{L}}$, where subscripts H $_{\mathrm{H}}$ and $\mathrm{L}_{\mathrm{L}}$ refer to a high and low measurement frequency, respectively) is

361 another measure of the IP effect that was popular in mineral exploration (Ward 1988). Figure 7b

362 shows that a negative PFE (i.e., increasing $\left|\rho_{\text {app }}^{*}\right|$ with increasing frequencies) is always observed

363 when $\varphi_{\text {app }}$ is positive. Just as with positive $\varphi_{\text {app }}$ values, a negative PFE is non-physical from the

364 perspective of IP mechanisms and another representation of negative IP effects in frequency

365 domain IP measurements.

366 In summary, this simulation of frequency dependent data demonstrates the possibility of a

367 wide range of $\varphi_{\text {app }}$ spectra, which can be very different from the spectra of an intrinsic polarizable

368 target. This has significant implications with respect to the interpretation of field-measured phase 369 curves.

370 6. Sandbox experiments

371 Laboratory sandbox experiments were conducted to verify the observations from numerical

372 modeling (Figure 8a). A sandbox $36 \mathrm{~cm}$ wide, $15 \mathrm{~cm}$ high and $55 \mathrm{~cm}$ long was filled with sand

373 fully saturated with tap water (resistivity of $40 \Omega \mathrm{m}$ at $25^{\circ} \mathrm{C}$ ). Four electrodes were deployed in

374 the central area of the sandbox with a $5 \mathrm{~cm}$ spacing. The distance between the electrodes and the

375 box wall was large enough to ignore boundary effects on the measurements. FDIP (from 0.1 to

$376100 \mathrm{~Hz})$ and TDIP data $(1 \mathrm{~Hz}$ waveform) were measured using an Ontash \& Ermac PSIP 
instrument and an IRIS Syscal Pro instrument, respectively. $\varphi_{\text {app }}$ and $M_{\text {app }}$ of the background sand was $-2 \mathrm{mrad}$ and $2 \mathrm{mV} / \mathrm{V}$ respectively, providing a low polarizability background matrix.

To simulate a scenario similar to the synthetic model in Section 5, a piece of the iron mineral magnetite (dimensions approximately $8 \mathrm{~cm}$ length, $4 \mathrm{~cm}$ height and $5 \mathrm{~cm}$ width) was buried between the middle two electrodes at $2 \mathrm{~cm}$ depth. The $\varphi_{\text {app }}$ collected using the dipole-dipole array is negative at high frequencies and then increases to positive values below $4 \mathrm{~Hz}$ (Figure 8b). The spectral shape of $\varphi_{\text {app }}$ in Figure $8 \mathrm{~b}$ is similar to the shape of the $0.1-200 \mathrm{~Hz}$ segment of the simulated blue $\varphi_{\text {app }}$ curve $\left(\left|\rho_{\text {bgk }}^{*}\right|=30 \Omega \mathrm{m}\right)$ in Figure $7 \mathrm{~b}$. The $M_{\text {app }}$ measured with the dipole-dipole array is $-42.5 \mathrm{mV} / \mathrm{V}$, also indicating a negative IP response. Its polarity is consistent with the $\varphi_{\text {app }}$ polarity at low frequencies. For the Wenner array measurement, a conventional negative $\varphi_{\text {app }}$ spectrum is observed (Figure 8c) as the polarizable magnetite falls within the positive sensitivity zones of this array (Figure $2 \mathrm{~b}$ ). The $M_{\text {app }}$ measured by the Wenner array is positive $(27.8 \mathrm{mV} / \mathrm{V})$, being consistent with the negative $\varphi_{\text {app }}$ recorded in the frequency domain. These laboratory experiments therefore confirm the observations from numerical modeling and theory.

\section{Conclusions}

In a heterogenous polarizable subsurface the apparent phase $\varphi_{\text {app }}$ recorded in surface fourelectrode FDIP measurements may be positive. The polarity of $\varphi_{\text {app }}$ is associated with the sensitivity distribution of a four-electrode measurement layout and is determined by the intrinsic phase and resistivity of the subsurface. Considerations of the sensitivity patterns of complex resistivity measurements theoretically confirm the occurrence of positive $\varphi_{\text {app }}$, i.e., for a nonpolarizable subsurface, placing a small, highly polarizable object in the negative and positive 
398 sensitivity zones will result in positive and negative $\varphi_{\text {app }}$, respectively. This is consistent with a 399 simplified electric circuit model, which physically explains the negative IP (i.e., the paradox of 400 current appearing to lag voltage) to result from the measured voltage drop across the potential 401 electrodes being divided by the input current at the current electrodes instead of the current flowing 402 through the impedance across the potential electrodes.

403 Numerical modeling shows the $\varphi_{\text {app }}$ polarity is dictated by the relative values of both the 404 intrinsic phase and the intrinsic resistivity of a polarizable heterogeneity compared to the 405 background medium. The control of the relative strength of the intrinsic resistivity on $\varphi_{\text {app }}$ results 406 from its influence on the sensitivity distribution of a measurement. In the case that the intrinsic 407 resistivity varies significantly with frequency, the $\varphi_{\text {app }}$ polarity can vary with frequency in FDIP 408 measurements, which results in $\varphi_{\text {app }}$ spectra that are very different from the intrinsic phase 409 spectrum. This finding is confirmed by laboratory sandbox experiments where $\varphi_{\text {app }}$ of a dipole410 dipole array on a buried piece of magnetite is negative from 100 to $4 \mathrm{~Hz}$ and then becomes positive 411 below $4 \mathrm{~Hz}$. Our results emphasize the need to accurately quantify error sources in FDIP

412 measurements as positive $\varphi_{\text {app }}$ measurements should be expected, are likely to be common in 413 heterogeneous systems and should not simply be discarded prior to further data processing e.g.

414 inversion. This observation is consistent with previously studied negative apparent chargeability 415 data in TDIP measurements.

\section{Acknowledgements}

417 This research was partly funded by the U.S. Department of Energy under grant DE-SC0016412 418 and a Rutgers University-Newark Graduate School Dissertation Fellowship award to C. Wang. 
419 Supplemental funding for this project was provided by the Rutgers University-Newark

420 Chancellor's Research Office. C. Wang thanks Sina Saneiyan (Rutgers University-Newark) for 421 guidance on the use of ResIPy. We thank Andreas Hördt, Konstantin Titov, Timothy Johnson and 422 an anonymous reviewer for their valuable comments that improved the quality of the paper.

\section{Data availability}

424 The data from this work is available upon request from the corresponding author.

\section{References}

426 Abdulsamad, F., Florsch, N., Schmutz, M. \& Camerlynck, C. (2016) Assessing the high

427 frequency behavior of non-polarizable electrodes for spectral induced polarization

428 measurements. J. Appl. Geophys., 135, 449-455, Elsevier B.V.

429 doi:10.1016/j.jappgeo.2016.01.001

430 Bate, B., Cao, J., Zhang, C. \& Hao, N. (2020) Spectral induced polarization study on enzyme

431 induced carbonate precipitations: influences of size and content on stiffness of a fine sand.

432 Acta Geotech., 8, Springer Berlin Heidelberg. doi:10.1007/s11440-020-01059-8

433 Binley, A. (2015) Tools and Techniques: Electrical Methods. Treatise Geophys. Second Ed.,

434 Vol. 11, Elsevier B.V. doi:10.1016/B978-0-444-53802-4.00192-5

435 Binley, Andrew \& Kemna, A. (2005) DC resistivity and induced polarization methods. in 436 Hydrogeophysics eds. Rubin, Y.\& Hubbard, S.S., pp. 129-156, Springer.

437 Blanchy, G., Saneiyan, S., Boyd, J., McLachlan, P. \& Binley, A. (2020) ResIPy, an intuitive 438 open source software for complex geoelectrical inversion/modeling. Comput. Geosci., 137, 439 104423, Elsevier Ltd. doi:10.1016/j.cageo.2020.104423 
440 Cole, K. s. \& Cole, R.H. (1941) Dispersion and Absorption in Dielectrics I. Alternating Current

441 Characteristics. J. Chem. Phys., 9, 341-351.

442 Dahlin, T. \& Loke, M.H. (2015) Negative apparent chargeability in time-domain induced

443 polarisation data. J. Appl. Geophys., 123, 322-332, Elsevier B.V.

444 doi:10.1016/j.jappgeo.2015.08.012

445 Flores, A., Kemna, A., Oberdörster, C., Zschornack, L., Leven, C., Dietrich, P. \& Weiss, H.

446 (2012) Delineation of subsurface hydrocarbon contamination at a former hydrogenation

447 plant using spectral induced polarization imaging. J. Contam. Hydrol., 136-137, 131-144,

$448 \quad$ Elsevier B.V. doi:10.1016/j.jconhyd.2012.06.001

449 Flores Orozco, A., Bücker, M., Steiner, M. \& Malet, J.P. (2018) Complex-conductivity imaging

450 for the understanding of landslide architecture. Eng. Geol., 243, 241-252, Elsevier.

$451 \quad$ doi:10.1016/j.enggeo.2018.07.009

452 Garcia-Artigas, R., Himi, M., Revil, A., Urruela, A., Lovera, R., Sendrós, A., Casas, A., et al.

453 (2020) Time-domain induced polarization as a tool to image clogging in treatment wetlands.

454 Sci. Total Environ., 724. doi:10.1016/j.scitotenv.2020.138189

455 Kelter, M., Huisman, J.A., Zimmermann, E. \& Vereecken, H. (2018) Field evaluation of

456 broadband spectral electrical imaging for soil and aquifer characterization. J. Appl.

457 Geophys., 159, 484-496, Elsevier B.V. doi:10.1016/j.jappgeo.2018.09.029

458 Kemna, A. (2000) Tomographic inversion of complex resistivity - Theory and application, $\mathrm{PhD}$

459 thesis, Ruhr-University of Bochum.

460 Komarov, V. (1960) Bases of application of the induced polarization method for prospecting of

$461 \quad$ ore deposits. Methodol. Tech. Explor., 23, 7-17. 
462 Komarov, V. (1980) Electrical prospecting with Induced Polarization method, Leningrad: Nedra 463 Press.

464 Lesmes, P. \& Frye, M. (2001) Influence of pore fluid chemistry on the complex conductivity and 465 induced polarization responses of Berea sandstone. J. Geophys. Res., 106, 4079-4090.

466 Liu, W., Chen, R., Cai, H., Luo, W. \& Revil, A. (2017) Correlation analysis for spread-spectrum 467 induced-polarization signal processing in electromagnetically noisy environments.

468 Geophysics, 82, E243-E256. doi:10.1190/GEO2016-0109.1

469 Luo, Y. \& Zhang, G. (1998) 2. Forward Theory of Spectral Induced Polarization. in Theory and $470 \quad$ Application of Spectral Induced Polarization, pp. 13-90, Society of Exploration $471 \quad$ Geophysicists. doi:10.1190/1.9781560801856.ch2

472 Mary, B., Saracco, G., Peyras, L., Vennetier, M., Mériaux, P. \& Camerlynck, C. (2016) Mapping 473 tree root system in dikes using induced polarization: Focus on the influence of soil water content. J. Appl. Geophys., 135, 387-396, Elsevier B.V. doi:10.1016/j.jappgeo.2016.05.005

475 Nabighian, M.N. \& Elliot, C.L. (1976) NEGATIVE INDUCED-POLARIZATION EFFECTS

Ntarlagiannis, D., Robinson, J., Soupios, P. \& Slater, L. (2016) Field-scale electrical geophysics 478 over an olive oil mill waste deposition site: Evaluating the information content of resistivity 479 versus induced polarization (IP) images for delineating the spatial extent of organic 480 contamination. J. Appl. Geophys., 135, 418-426, Elsevier B.V. $481 \quad$ doi:10.1016/j.jappgeo.2016.01.017

482 Pelton, W.H., Wards, S.H., Hallof, P.G., Sill, W.R. \& Nelson, P.H. (1978) Mineral 483 Discrimination and Removal of Inductive Coupling with Multifrequency IP. Geophyics, 43, 

$588-609$.

485 Saneiyan, S., Ntarlagiannis, D., Ohan, J., Lee, J., Colwell, F. \& Burns, S. (2019) Induced 486 polarization as a monitoring tool for in-situ microbial induced carbonate precipitation (MICP) processes. Ecol. Eng., 127, 36-47, Elsevier. doi:10.1016/j.ecoleng.2018.11.010

488 Saneiyan, S., Ntarlagiannis, D., Werkema, D.D. \& Ustra, A. (2018) Geophysical methods for 489 monitoring soil stabilization processes. J. Appl. Geophys., 148, 234-244, Elsevier B.V. doi:10.1016/j.jappgeo.2017.12.008

491 Seigel, H.O. (1959) MATHEMATICAL FORMULATION AND TYPE CURVES FOR INDUCED POLARIZATION. GEOPHYSICS, 24, 547-565. doi:10.1190/1.1438625

493 Slater, L.D., Choi, J. \& Wu, Y. (2005) Electrical properties of iron-sand columns: Implications 494 for induced polarization investigation and performance monitoring of iron-wall barriers. Geophysics, 70, G87. doi:10.1190/1.1990218

496 Slater, L.D. \& Lesmes, D. (2002) IP interpretation in environmental investigations. Geophysics, 497 67, 77-88. doi:10.1190/1.1451353

498 Sumner, J.S. (1976) Principles of induced polarization for geophysical exploration, Elsevier. 499 Voorhis, G.D. Van, Nelson, P.H. \& Drake, T.L. (1973) COMPLEX RESISTIVITY SPECTRA OF PORPHYRY COPPER MINERALIZATION. GEOPHYSICS, 38, 49-60.

Ward, S.H. (1988) The Resistivity and Induced Polarization Methods. Symp. Appl. Geophys. to Eng. Environ. Probl. 1988, pp. 109-250, Environment and Engineering Geophysical Society. doi:10.4133/1.2921804

505 Wong, J. (1979) An electrochemical model of the induced-polarization phenomenon in 


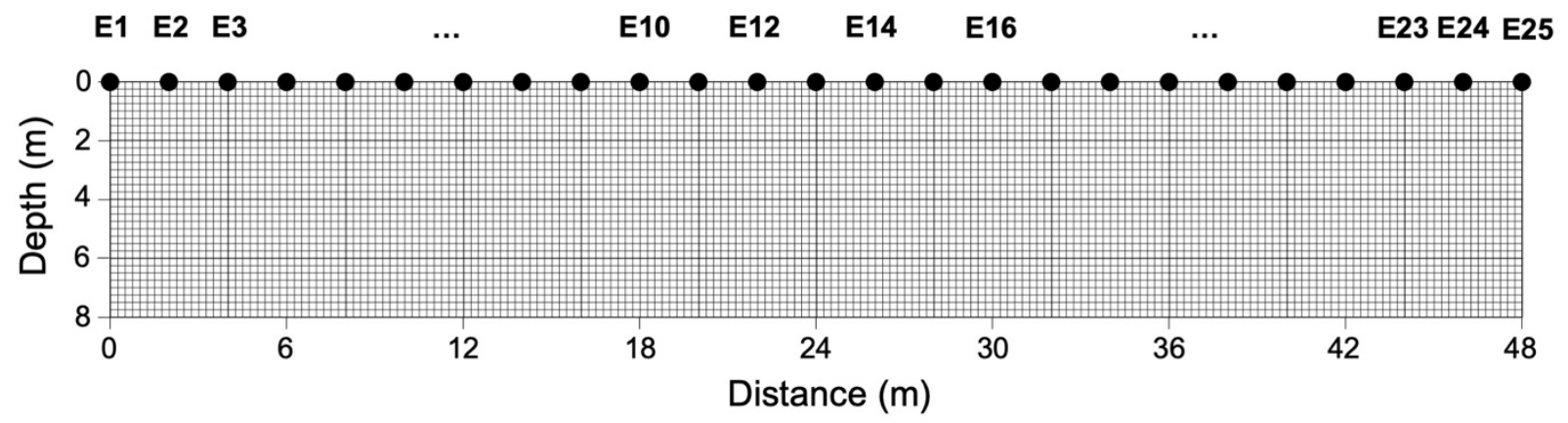

508

509 Figure 1. Numerical modeling set up with 25 electrodes (E1 to E25) on a model space using 0.25

$510 \times 0.25 \mathrm{~m}$ mesh cells.

511 

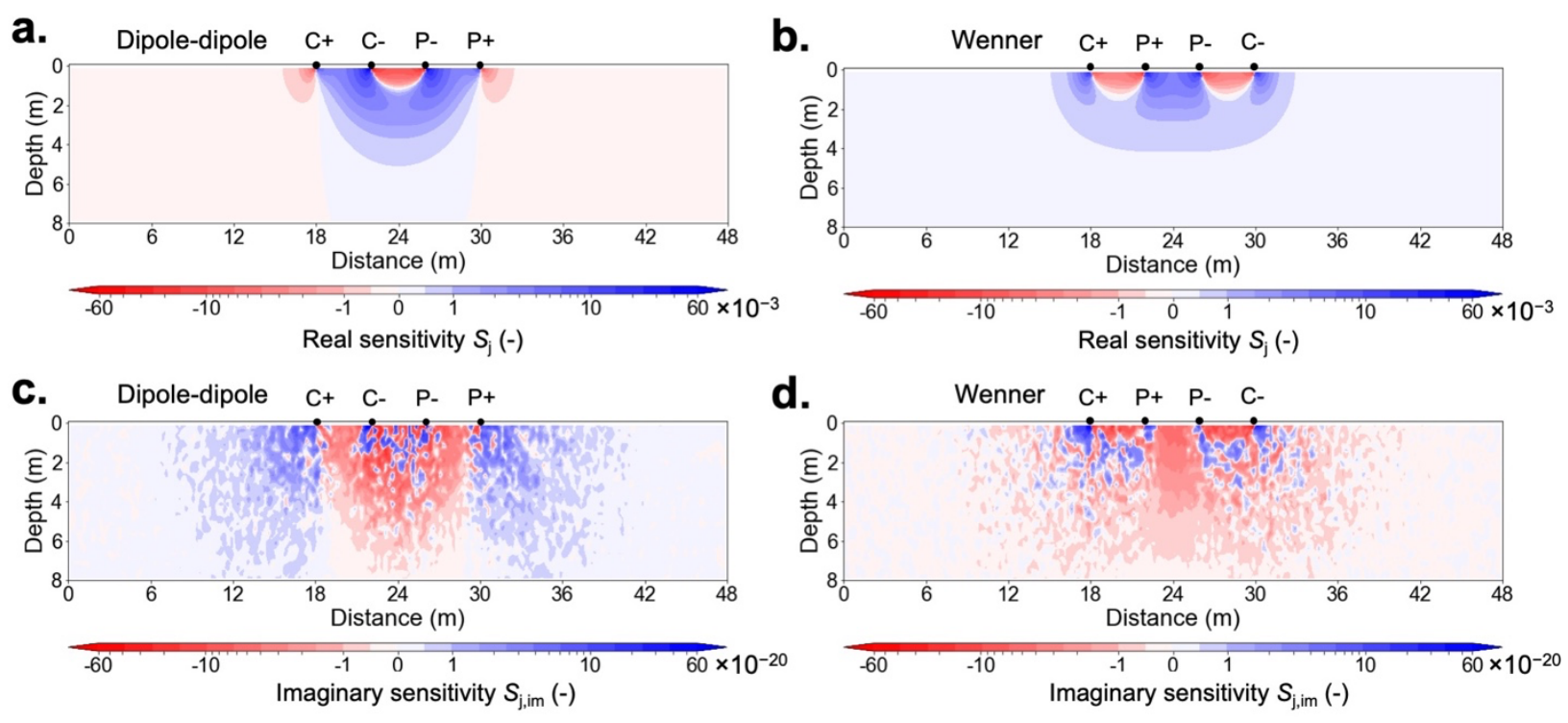

514 Figure 2. Sensitivity distribution of complex resistivity measurements using electrodes E10, E12,

515 E14 and E16 for a $100 \Omega \mathrm{m}$ and $-1 \mathrm{mrad}$ homogeneous half space. (a) Real sensitivity of dipole-

516 dipole array $(\mathrm{E} 10=\mathrm{C}+, \mathrm{E} 12=\mathrm{C}-, \mathrm{E} 14=\mathrm{P}-, \mathrm{E} 16=\mathrm{P}+)$. (b) Real sensitivity of Wenner array $(\mathrm{E} 10=\mathrm{C}+$,

517 E12=P+, E14=P-, E16=C-). (c) Imaginary sensitivity of dipole-dipole array. (d) Imaginary

518 sensitivity of Wenner array. 

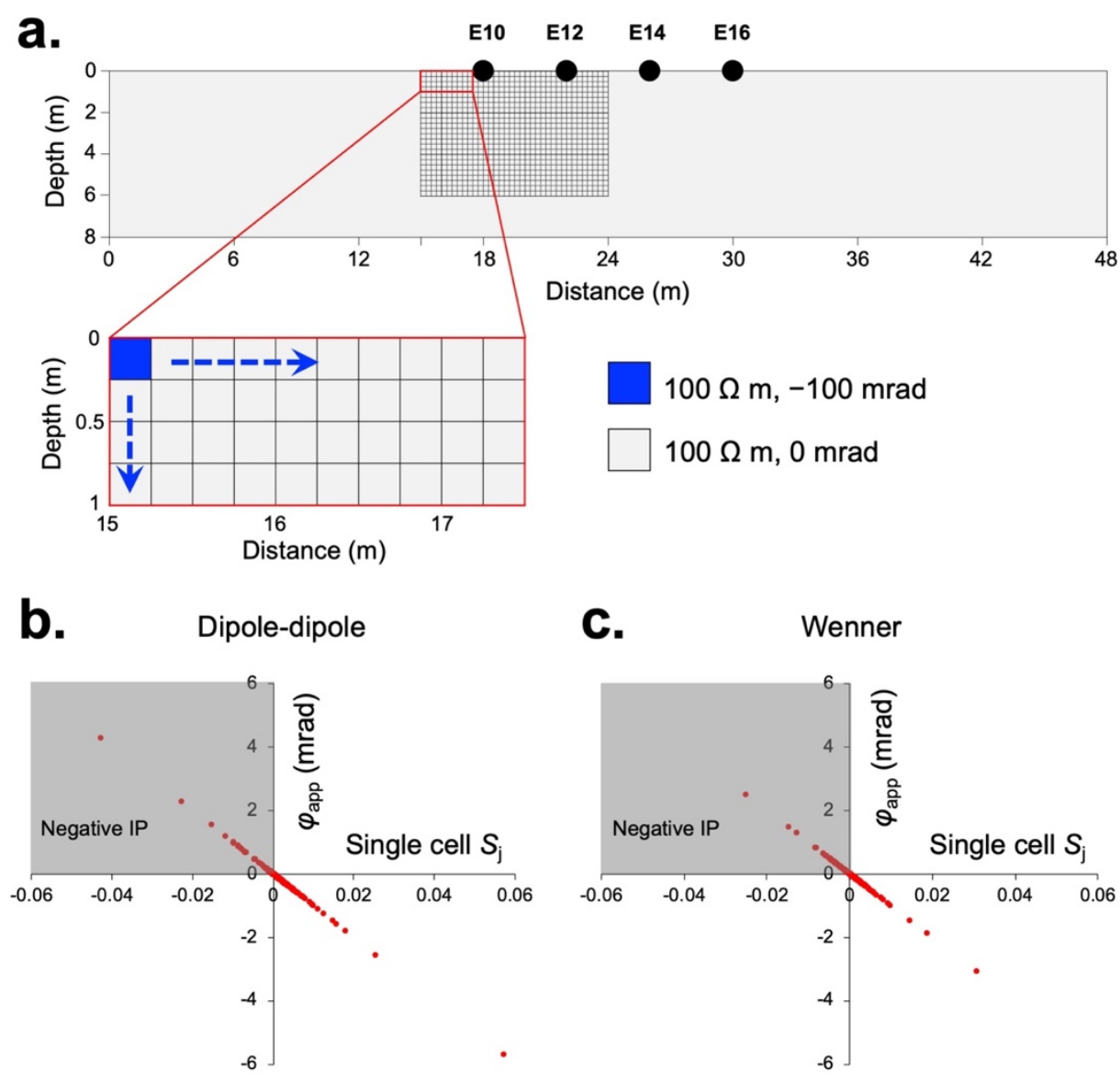

522 Figure 3. Numerical modeling of the influence of sensitivity polarity on the $\varphi_{\text {app }}$ polarity. (a).

523 Illustration of the model configuration; a polarizable cell (blue) moves to the right and down one

524 cell by one cell (in the zoomed in figure) to cover the region of 15 to $24 \mathrm{~m}$ distance and 0 to $6 \mathrm{~m}$

525 depth (meshed region in the zoomed out figure); with the polarizable cell in each location, $\varphi_{\text {app }}$ for 526 a dipole-dipole array $(\mathrm{E} 10=\mathrm{C}+, \mathrm{E} 12=\mathrm{C}-, \mathrm{E} 14=\mathrm{P}-, \mathrm{E} 16=\mathrm{P}+)$ and a Wenner array $(\mathrm{E} 10=\mathrm{C}+, \mathrm{E} 12=\mathrm{P}+$, 527 E14=P-, E16=C-) were computed; (b) and (c). $\varphi_{\text {app }}$ for a dipole-dipole (b) and Wenner (c) array 528 versus the sensitivity $S_{\mathrm{j}}$ (unitless) of the single cell containing the polarizable cell (blue cell in 3a);

529 Grey shaded quadrants highlight the negative IP responses. 

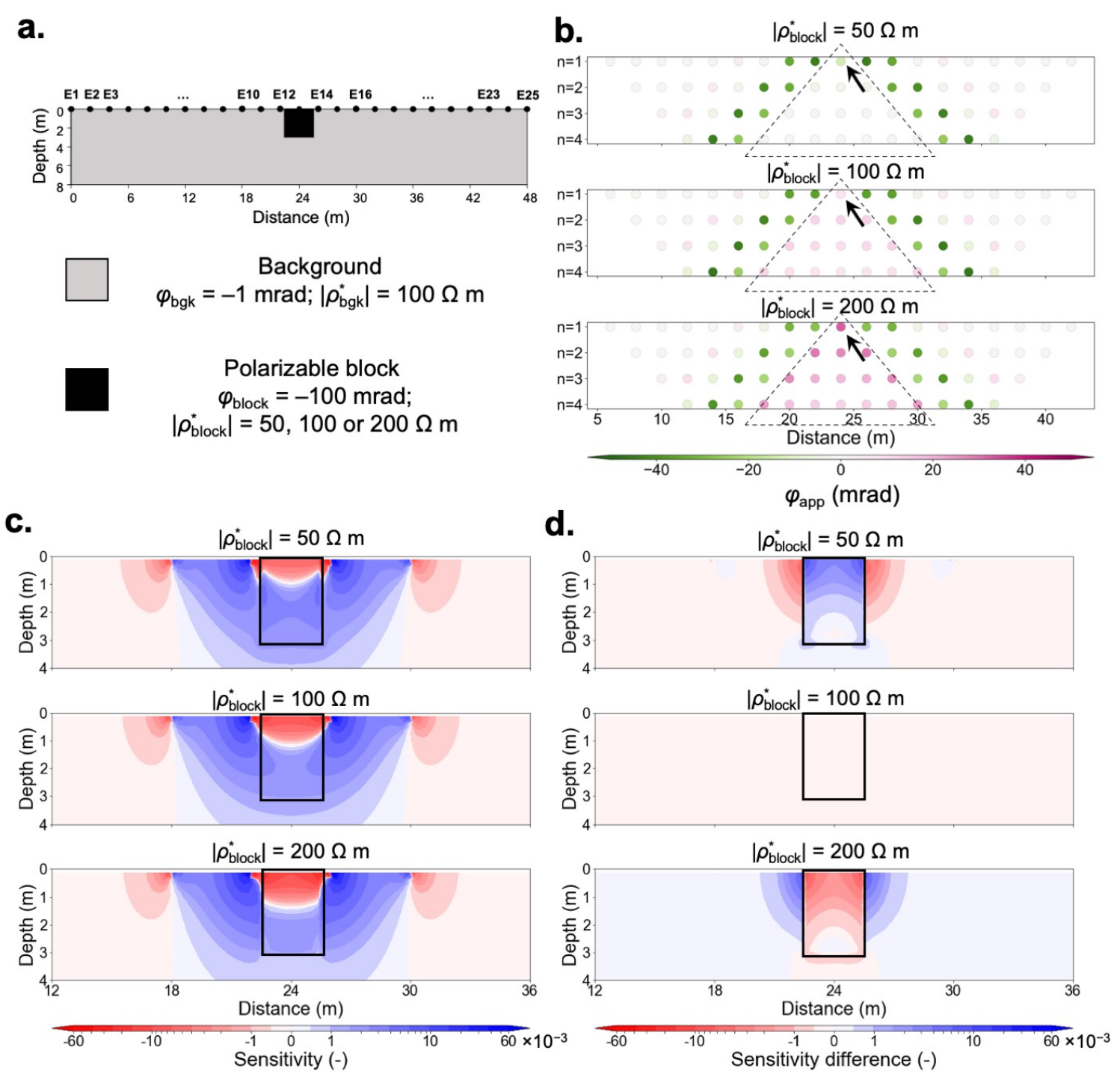

531 Figure 4. Influence of resistivity heterogeneity on the $\varphi_{\text {app }}$ polarity. (a). Synthetic model settings.

532 (b). Pseudosection of $\varphi_{\text {app }}$ at various values of $\left|\rho_{\text {block }}^{*}\right|\left(\left|\rho_{\text {block }}^{*}\right|=100 \Omega \mathrm{m}\right.$ is the homogeneous

533 resistivity condition); data within the dashed triangles are influenced by $\mid \rho_{\text {block }}^{*}$. (c). Sensitivity

534 distribution of the single four-electrode measurement pointed out by the arrow in (b) with various

$535\left|\rho_{\text {block }}^{*}\right|$ corresponding to the pseudosections. (d). Sensitivity difference relative to that of $\left|\rho_{\text {block }}^{*}\right|$ $536=100 \Omega \mathrm{m}$. 

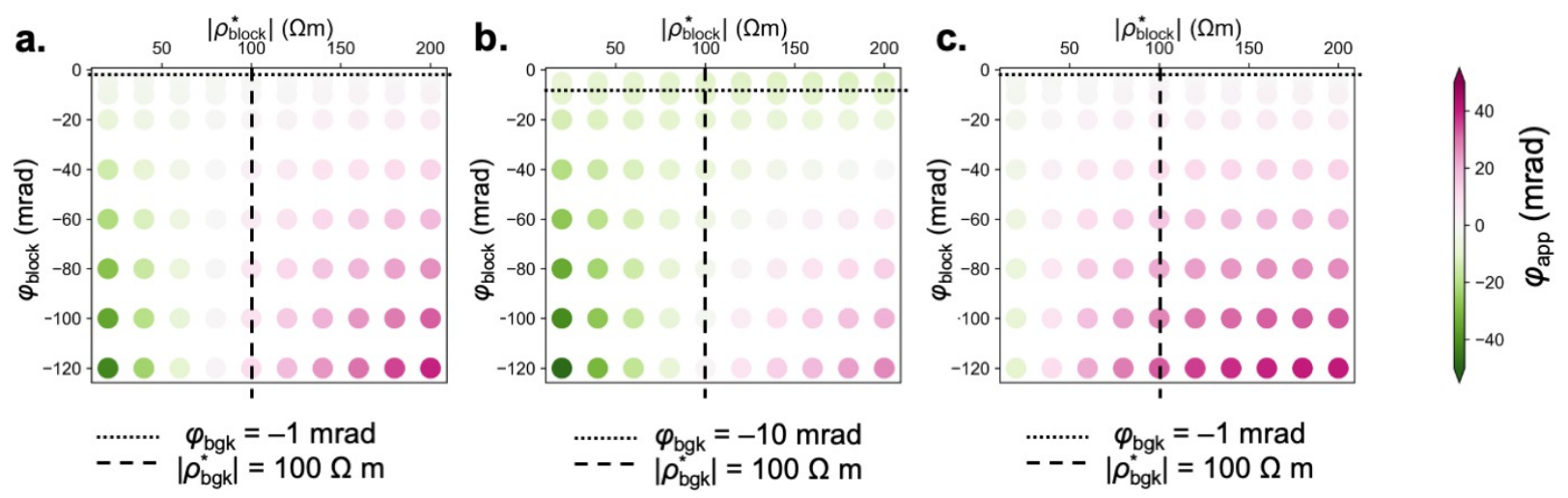

538 Figure 5. Impacts of $\left|\rho_{\text {block }}^{*}\right|$ and $\varphi_{\text {block }}$ on the modeled $\varphi_{\text {app }}$ under various conditions. (a) and (b).

$539 \varphi$ app modeled using a dipole-dipole array $(\mathrm{E} 10=\mathrm{C}+, \mathrm{E} 12=\mathrm{C}-, \mathrm{E} 14=\mathrm{P}-, \mathrm{E} 16=\mathrm{P}+)$ for the synthetic

540 structure shown in Figure 4a under various background settings (indicated by dotted and dashed

541 lines). (c). $\varphi_{\text {app }}$ modeled with the same settings as (a) but with vertical extent of polarizable block 542 in Figure $4 \mathrm{a}$ reduced to be between 0 and $1 \mathrm{~m}$. 

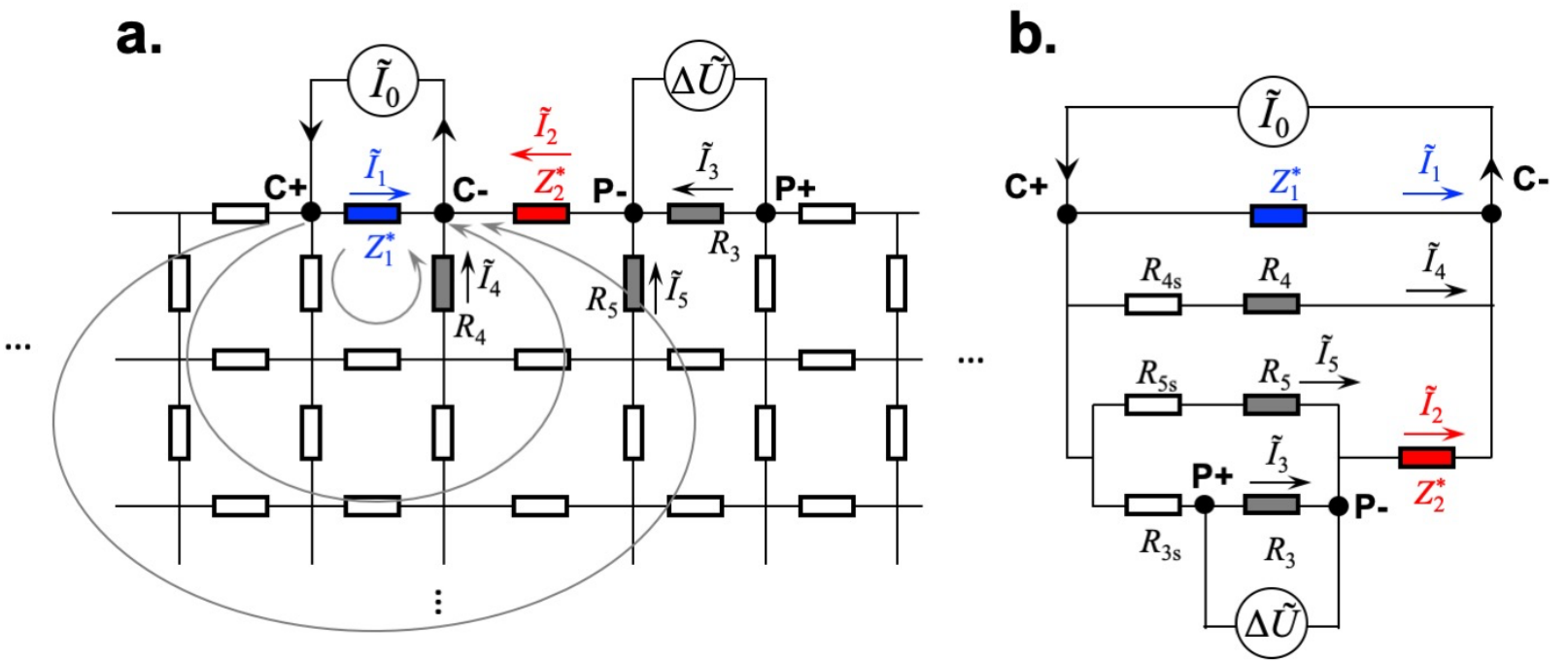

545 Figure 6. (a). Electrical conduction through the subsurface modeled as a resistor/impedance

546 network circuit; grey arrows illustrate idealized current flow directions in a real subsurface space

547 for comparison; (b) A simplified equivalent linear electrical circuit of the circuit conceptualized in 548 (a). 
a.
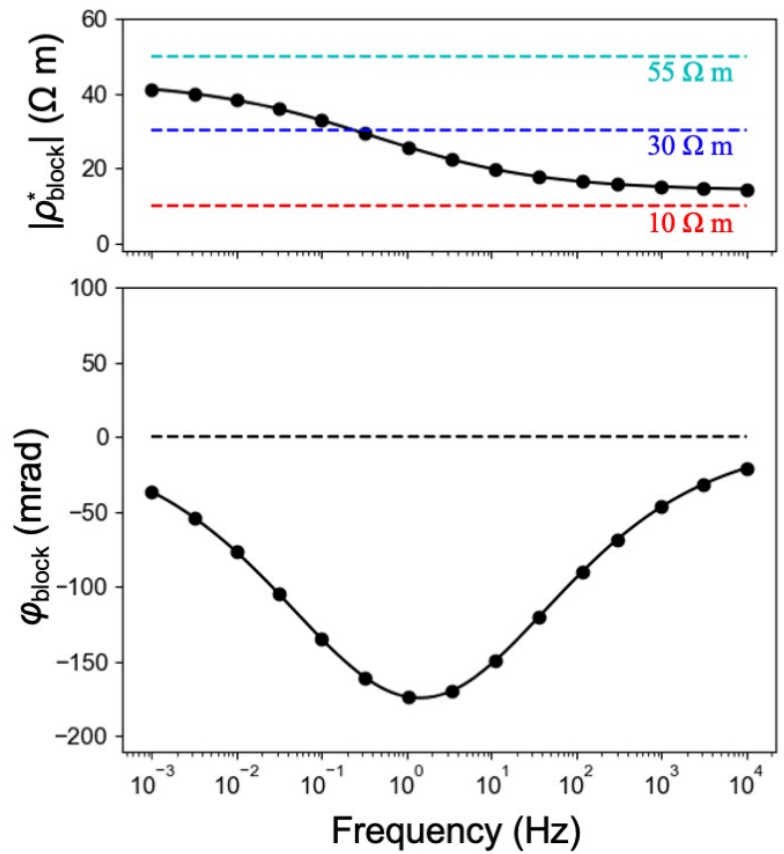
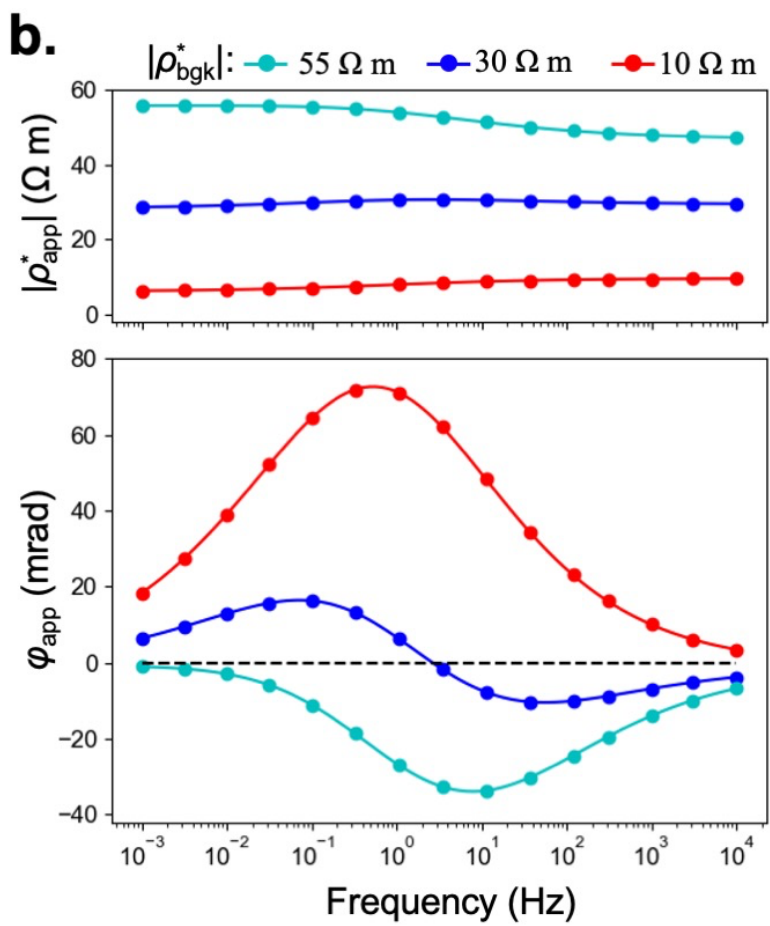

551 Figure 7. Simulation based on a polarizable block with frequency-dependent complex resistivity

552 using model structure shown in Figure 4a (a). Intrinsic resistivity and phase spectra of the

553 polarizable block and the selection of frequency-independent background resistivity (colored

554 dashed lines); black dashed line represents $\varphi_{\text {block }}=0 \mathrm{mrad}$; (b). $\left|\rho_{\text {app }}^{*}\right|$ and $\varphi_{\text {app }}$ spectra under 555 different $\left|\rho_{\mathrm{bgk}}^{*}\right|$ conditions; black dashed line represents $\varphi_{\text {app }}=0 \mathrm{mrad}$. 


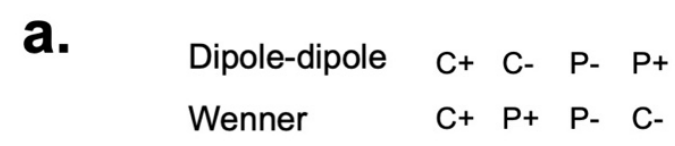
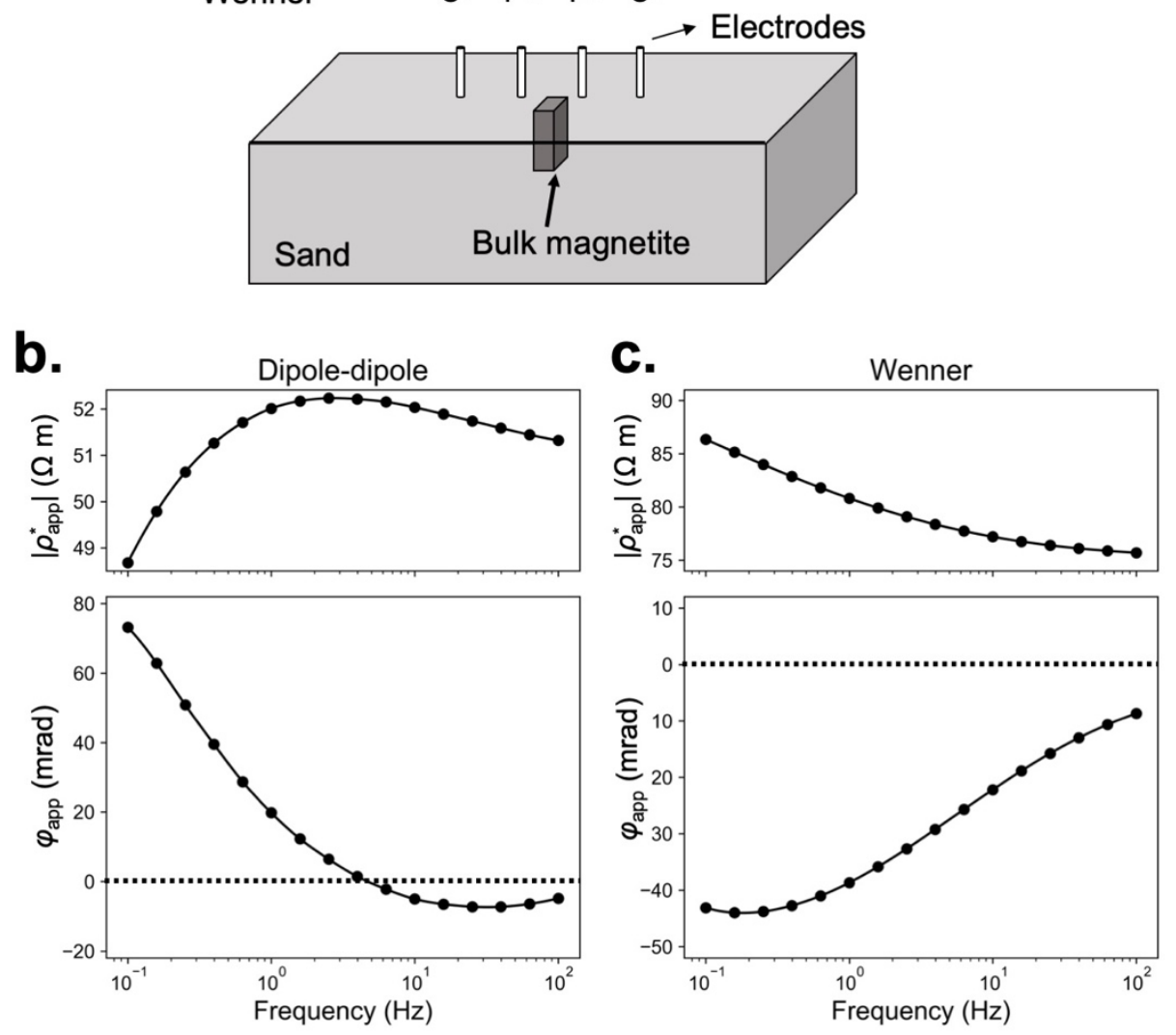

558 Figure 8. Sandbox experiments. (a) Schematic diagram of sandbox experimental set-up. (b). $\left|\rho_{\text {app }}^{*}\right|$ 559 and $\varphi_{\text {app }}$ spectra measured by dipole-dipole array; black dashed line represents $\varphi_{\text {app }}=0 \mathrm{mrad}(\mathrm{c})$

$560 \quad \rho_{\text {app }}^{*} \mid$ and $\varphi_{\text {app }}$ spectra measured by Wenner array; black dashed line represents $\varphi_{\text {app }}=0 \mathrm{mrad}$. 